\title{
Método para avaliar desenvolvimento sustentável: técnicas para escolha e ponderação de aspectos e dimensões
}

\author{
Osmar Siena UNIR
}

\section{RESUMO}

Materializar o conceito desenvolvimento sustentável é um problema complexo, pois as bases conceituais sobre as questões envolvidas não estão consolidadas. Não há consenso sobre o que medir como medir e, principalmente, sobre como ponderar e combinar dados. Este trabalho discute e testa método para avaliação do desenvolvimento na perspectiva do desenvolvimento sustentável, considerando o sistema a ser avaliado composto por subsistemas (pessoas e ecossistema), oito dimensões e duas categorias. As dimensões contemplam aspectos, que são características do sistema que devem ser consideradas para a avaliação. A consulta a atores chaves do sistema em foco precede a escolha e ponderação dos aspectos e ponderação das dimensões. Discute-se a adoção da análise fatorial para redução do número de aspectos para avaliação. São calculados índices agregados para dimensões, subsistemas e para o sistema analisado. Para teste da abordagem proposta foi realizada uma aplicação tendo como referência o estado de Rondônia (Brasil).

\section{PALAVRAS-CHAVE}

Desenvolvimento sustentável, sustentabilidade, indicadores e índices.

\section{Method to evaluate sustainable development: techniques for choice and balance of aspects and dimensions}

\begin{abstract}
Materialize the concept sustainable development is a complex problem, therefore the conceptual bases on the involved questions are not consolidated. There is no consensus on what to measure, how to measure and, principally, on as to ponder and combine data. This work argues and tests method for evaluation of the development in the perspective of sustainable development, considering the system to be evaluated composed of subsystems (people and ecosystem), eight dimensions and two categories. The dimensions contemplate aspects that are characteristic of the system that must be considered for the evaluation. Consultation to system evaluated key actors precedes the choice and balance of the aspects and dimensions. It is argued the adoption of the factorial analysis as the technique for reduction of the number of aspects for evaluation. Indices aggregate for dimensions, subsystems and for the system are calculated. For test of the approach proposal is carried through an application having as reference the state of Rondônia (Brazil).
\end{abstract}




\section{INTRODUÇÃO}

Independentemente do emaranhado de visões, é fato que o desenvolvimento sustentável está presente como questão fundamental nas políticas de governos. Por isso, é cada vez mais importante a identificação de conjuntos de indicadores que permitam avaliar desenvolvimento sustentável. Indicadores devem ser desenvolvidos para fornecer base para tomada de decisão em todos os níveis (AGENDA 21, 1995). Esta constatação acelerou o desenvolvimento teórico e prático de conjuntos de indicadores (HARDI et al., 1997; BELLEN, 2005).

Um problema preliminar no desenvolvimento de indicadores é que não há uma clara definição de desenvolvimento sustentável, visto que as diferentes culturas e os diferentes grupos tendem a definir sustentabilidade em termos de sua visão de mundo e de seus propósitos e interesses (KELLY, 1998). Assim, o problema não é a falta de idéias sobre indicadores, mas a seleção de um conjunto apropriado (MOLDAN; BILLHARZ; MATRAVERS, 1997).

Várias aproximações para conjuntos de indicadores de desenvolvimento sustentável estão sendo desenvolvidas, testadas e aperfeiçoadas. No entanto, não existe metodologia consolidada. Uma das lacunas diz respeito ao sistema de agregação de dados: como escolher e priorizar ou ponderar dimensões e aspectos para, ao final, expressar o resultado em índice de desenvolvimento sustentável.

Este artigo se ocupa, principalmente, destes aspectos: mecanismos de operacionalização do conceito de desenvolvimento sustentável, discutindo e testando técnicas para escolha e ponderação de aspectos e ponderação das dimensões. Para verificar a adequação da abordagem proposta, realiza-se uma aplicação tendo como referência o estado de Rondônia (Brasil).

\section{INDICADORES DE DESENVOLVIMENTO SUSTENTÁVEL}

Cinco são os modelos mais influentes em relação às medidas de desenvolvimento sustentável. Os modelos baseados na economia refletem as relações insumos/produtos e evoluíram seguindo três fases: na primeira, compara o fluxo de bens e serviços de firmas com o consumo doméstico (JACOBS, 1993); os modelos de equilíbrio de materiais e energia incorporaram a produção e o uso de bens com a conseqüente descarga de desperdício no ambiente; e o modelo poluição/depleção vincula o sistema econômico ao sistema de suporte à vida natural por meio da extração de recursos, numa direção, e a descarga de resíduos, em outra (TIE-
TENBERG, 1992). O modelo de estresse-resposta focalizava na sua origem os estresses impostos sobre as pessoas pelo ambiente. Evoluiu para o modelo pressão-estado-resposta (P-S-R) (OECD, 1997; 2000) e para a versão mais recente, que é o modelo força motriz-estado-resposta (DF-S-R) (OECD, 2000; UNCSD, 1996; 2001; 2006), que inclui quatro categorias: o estressor de atividades; estresse ambiental; resposta ambiental; e respostas humanas individuais e coletivas. O modelo de temas ou de três componentes (HARDI et al., 1997) inclui os campos social, econômico e ambiental. O modelo do capital múltiplo considera que as categorias capital artificial, capital natural, capital social e humano são dons que devem ser preservados, enriquecidos ou substituídos, quando consumidos (WORLD BANK, 2000; 2001). Em uma das versões do modelo do bem-estar humano e do ecossistema vinculados, são identificados quatro domínios de indicadores: ecossistema; interações; pessoas; e síntese (HODGE, 1995). Tendo por base um desses modelos, várias aproximações para conjunto de indicadores e medidas de desenvolvimento sustentável estão sendo discutidas, desenvolvidas e testadas (BOSSEL, 1999; HARDI; ZDAN, 1997; HARDI et al., 1997; HODGE, 1995; HODGE; HARDI; BELL, 1999; IBGE, 2004; IMBACH et al., 1997; IWGSDI, 2000; 2001; MEADOWS, 1998; OCED, 2000; PRESCOTTALLEN, 1999 2001; UNCDS, 1996; 2001; 2003; 2006; WORLD BANK, 1996). Ao realizar um levantamento, sem considerar a área de atuação das diferentes ferramentas de avaliação, Bellen (2005) identificou 18 (dezoito) metodologias ou instrumentos de avaliação da sustentabilidade mais referenciadas na literatura. No entanto, constata-se que há problemas conceituais e de medidas não resolvidos adequadamente pelas experiências em curso. Um deles é quanto à seleção e ponderação das questões relevantes para avaliação. $\mathrm{O}$ outro diz respeito à agregação de dados.

A metodologia mais difundida tem o patrocínio da Comissão sobre Desenvolvimento Sustentável (CSD) das Nações Unidas, tendo por base o modelo pressão ou força motriz - estado - resposta (DF/S/R). Sua primeira versão foi publicada em 1996 (UNCSD, 1996), contendo uma lista de indicadores agrupados de acordo com os capítulos da Agenda $21 \mathrm{em}$ quatro grandes categorias: sociais, econômicos, ambientais e institucionais. $\mathrm{O}$ arcabouço pode ser representado por uma matriz, onde essas categorias formam a estrutura horizontal. A estrutura vertical é organizada em categorias chamadas de pressão ou força motriz, estado e resposta, baseadas nas relações causais entre os estresses gerados pelas atividades humanas e as mudanças no estado do ambiente social e natural. Embora essa metodologia seja útil como um guia geral, pois apresenta descrição detalhada de indicadores, a mais séria limitação desse tipo de 
aproximação é o modelo em si mesmo. Apesar de captar os vínculos causais dentro do sistema, ela falha na obtenção de informação sobre a estrutura e o comportamento do sistema no qual as decisões são tomadas (KELLY, 1998), não é completamente apropriada para descrever as interações e não incorpora compreensivamente os aspectos sociais do bem-estar (CUSTANCE; HILLIER, 1998).

Devido a críticas de especialistas e a partir dos resultados de testes em diversos países, a metodologia da UNCSD sofreu aprimoramentos sucessivos. Primeiro foi alterado o foco; passou a ser organizada em temas e subtemas, em número de quinze e dezoito, visando sua adequação ao processo de tomada de decisão; foi também iniciada a discussão sobre a divisão dos indicadores em essenciais e não-essenciais (são importantes para algumas regiões, mas não para todas) (UNCSD, 2001). Em 2003 foi reconhecida a necessidade de aprimorar a metodologia no que se refere à agregação de indicadores; são discutidas várias alternativas, mas não há clareza sobre o rumo a seguir, recomendando apenas o cálculo de índices por grandes áreas (UNCSD, 2003; 2006). Em sua última revisão (UNCSD, 2006), consolida a divisão de indicadores em essenciais (40), não-essenciais (39) e outros indicadores (13) para os quais ainda não há metodologia desenvolvida. A metodologia passa a ter uma configuração multitemática, tornando-se mais flexível e de melhor compreensão pelo usuário. Entretanto, as questões relacionadas à ponderação dos temas e subtemas e, conseqüentemente, a agregação dos dados continuam em aberto.

Um trabalho que avança na discussão desses aspectos é o System Assessment Method (SAM), desenvolvido e testado pela The World Conservation Union (IUCN), sob a liderança de Prescott-Allen (1997; 1999). Ele é a base para o Método de Avaliação do Bem-Estar das Nações implementado por Prescott-Allen (2001). Como o SAM utiliza uma ferramenta chamada de Barômetro de Sustentabilidade para apresentação de seus resultados, também é conhecido com este nome. O SAM é um método para avaliar as condições ambientais e humanas e o progresso em direção ao desenvolvimento sustentável. A hipótese subjacente é a de que desenvolvimento sustentável é uma combinação do bemestar humano e do ecossistema. Com base nesta suposição, o método trata o bem-estar humano e do ecossistema como igualmente importantes. A informação é organizada em dois subsistemas, humano e ecossistema, cada qual dividido em cinco dimensões que congregam tópicos considerados igualmente relevantes. Os usuários identificam os elementos chaves de cada dimensão e os indicadores de cada elemento, decidindo também os objetivos para os subsistemas e para os elementos, bem como os critérios de desempenho para os indicadores. Os critérios permitem que as medidas do indicador sejam marcadas numa escala de cinco faixas. Estas faixas correspondem ao Barômetro de Sustentabilidade (PRESCOTT-ALLEN, 2001). A decisão sobre critérios de desempenho tem por base fatores tais como taxa sustentável estimada, padrões observados, as metas nacional-internacionais, opinião de peritos e consenso dos participantes. Os escores dos indicadores são combinados por elementos e estes em índices da dimensão. Não há padrão rígido para ponderação. Os índices das dimensões são considerados de igual importância e agregados por subsistemas. Os índices dos subsistemas são combinados e geram o índice geral.

O método SAM ou de Avaliação do Bem-Estar utiliza um processo inovador para combinar os dados e possibilita uma aproximação detalhada da mensuração de progresso. Por meio do barômetro de sustentabilidade, dá um retrato visual do estado atual do desenvolvimento. Ocorre que a aproximação também não apresenta método para ponderação dos aspectos e despreza o fato de que as dimensões nem sempre têm a mesma importância para todos os sistemas. Questão central que continua problemática é o número de elementos e, por conseqüência, o número de indicadores, para avaliação. Como não emprega técnicas para redução, trabalha com um número elevado de aspectos e indicadores, o que dificulta sua compreensão e utilização pelos tomadores de decisão.

Existem outras aproximações que empregam algum tipo de método para agregação de dados, entre as quais se pode destacar: Painel de Sustentabilidade (IISD, 2005); Índice de Desenvolvimento Humano (UNDP, 1996; 2000); Pegada Ecológica (WACKERNAGEL et al., 1997); Indicador de Progresso Genuíno (COBB et al., 1995). Entretanto, quase todas são criticadas por não apresentarem no conjunto método seguro para avaliação.

Desse modo, nas aproximações correntes não há uma metodologia consolidada para escolha, redução e ponderação dos aspectos e dimensões para avaliação. Observa-se também que há pouca informação pública sobre os processos de agregação.

Uma das complexidades para reduzir o número de aspectos e agregar informações em índices reside em estabelecer ponderação dos componentes do sistema, sem desprezar ou tornar o processo subjetivo. Além disso, cada sistema possui prioridades distintas e enfrenta problemas diferentes. A agregação requer que as questões sejam convertidas em valores padronizados à mesma referência. $\mathrm{O}$ objetivo da padronização é melhorar o entendimento da proporção ou valor para cada questão, com escores expressos na mesma dimensão, o que permite uma melhor comparabilidade dos resultados. É possível identificar alguns critérios para realizar a agregação: (a) usando ponderação baseada em padrões em relação aos objetivos, estabelecidos cientificamente no plano internacio- 
nal, por meio de Painel de especialistas; (b) utilizar valores definidos pela sociedade, por meio de Survey, painéis com atores representativos ou métodos de decisão multicritérios; (c) utilizar método Delphi, análise multicritério ou método da distância das metas para ponderar aspectos ou indicadores onde há reconhecida dificuldade de comparações científicas; e (d) utilizar métodos em seqüência; ponderação com base em análise científica e em julgamento de valor.

Como todos os métodos carregam alguma carga de subjetividade, o processo de agregação deve ser transparente, independente do método adotado. $\mathrm{O}$ usuário deve ter informação de como os dados foram transformados. A transparência é essencial para que os responsáveis pelas decisões compreendam a utilidade de indicadores ou índices, bem como ter ciência sobre os significados e as limitações dos resultados apresentados.

\section{MÉTODO PARA AVALIAR DESENVOLVIMENTO SUSTENTÁVEL}

A partir da concepção geral contida no System Assessment Method (SAM), desenvolvido e testado pela The World Conservation Union (IUCN), que trata o sistema a ser analisado composto de dois subsistemas (pessoas e ecossistema), considerados igualmente importantes, pois a hipótese subjacente é a de que desenvolvimento sustentável é uma combinação do bem-estar humano e do ecossistema,

de encontrar os aspectos relevantes. O terceiro diz respeito à agregação dos dados: enquanto o método para Avaliar Bem-Estar procura atribuir pesos iguais aos indicadores ou ponderá-los de forma ad hoc, o método discutido prevê atribuição de pesos para os aspectos e dimensões atribuídos pelos interessados, além de adotar técnica para reduzir o número de aspectos. Os Princípios Bellagio para avaliar sustentabilidade são adotados como referências para validação da proposta (IMBACH et al., 2001).

O método discutido neste trabalho dirige o foco em toda a extensão do processo relacionado com o bem-estar das pessoas e ecossistema, com atenção especial para identificação dos aspectos e indicadores relevantes para avaliar sustentabilidade, utilizando o conceito econômico de estoque e fluxo. Estoques são indicadores de estado de um sistema e sua resposta no tempo. Fluxos podem ser considerados como indicadores de mudança. Estoques descrevem o estado do sistema em qualquer momento particular e são acumulações da história passada do sistema. Fluxos são os insumos ou produtos que aumentam ou diminuem os estoques (MEADOWS, 1998).

São consideradas duas categorias, Capacidades e Desafios (estoques) e Processos (fluxos), com o sistema a ser avaliado considerado em duas perspectivas ou dois subsistemas: pessoas e ecossistema. Uma geração herda ou recebe recursos que são utilizados para satisfazer suas próprias necessidades e desejos e os transfere para as gerações futuras. Uma geração também herda uma série de desafios, muitos trazidos de várias gerações. Indicadores de capacidades e desafios permitem avaliar sustentabilidade do desenvolvimento uma vez que enfatizam a necessidade de considerar os impactos das ações correntes sobre as futuras gerações. Processos incluem atividades que usam recursos para produção de bens,

este trabalho discute métodos e técnicas para escolha, ponderação e redução do número de aspectos e ponderação das dimensões para avaliação. O pressuposto é que aspectos e dimensões nem sempre têm a mesma importância para todos os subsistemas e sistemas, bem como o fato de que o elevado número de aspectos e indicadores dificulta a compreensão e a utilização dos resultados da avaliação pelos tomadores de decisão. Do método sistêmico para Avaliar Bem-Estar ou SAM (PRESCOTT-ALLEN, 1999; 2001) vem a concepção de considerar o sistema composto de dois subsistemas. A solução proposta difere do referido método em relação a três aspectos. Primeiro, por incluir duas categorias: para avaliar a condição dos recursos e para vincular explicitamente o processo com a tomada de decisões. O segundo é sobre a forma serviços e condições que são utilizados por uma geração. Indicadores de processo focalizam sobre os vínculos entre desenvolvimento sustentável e tomada de decisão e sobre o bem-estar corrente.

São consideradas quatro dimensões para cada subsistema. Essas dimensões, que podem ser fixas ou obtidas por meio de consulta ao grupo de interesse, representam as grandes preocupações que devem ser incluídas na avaliação e servem também para os agrupamentos de aspectos relevantes. Para o subsistema humano as dimensões escolhidas inicialmente para este trabalho são: Valores/atitudes e Organização/Poder, População e Saúde, Conhecimento e Cultura, e Riqueza e Renda; para o ecossistema, as dimensões adotadas são: Solo, Floresta e Água, Manutenção da Biodiversidade, Es- 
pécies e População (Gene) e Uso dos Recursos. Os aspectos representativos para cada uma das dimensões, e conseqüentemente os indicadores, variam de acordo com o sistema a ser avaliado. Sempre que possível, foi localizado um indicador representativo para cada aspecto.

O processo para operacionalização do método discutido, contendo 8 (oito) etapas, está ilustrado na Figura 1.

O sistema a ser avaliado, de acordo com cada uma das categorias e subsistemas, compreende as pessoas dentro do ecossistema e as interações entre elas. As interações consistem de fluxos do ecossistema para as pessoas (benefícios e estresses) e fluxos das pessoas para o ecossistema (estresses e benefícios). Um sistema pode ser composto por diferentes níveis espaciais (administrativo, ecológico, hidrológico, etc.).

Aspectos são preocupações chaves. São características do ecossistema ou da sociedade em termos de recursos e desafios ou processos, que devem ser consideradas para se ter uma visão adequada de suas condições. Aspectos são agrupados em dimensões predeterminadas e contemplam as necessidades e condições do sistema em foco e, ao mesmo tempo, permitem comparação com avaliações em outros locais, possibilitando a combinação em índices de bem-estar humano e do ecossistema. Diferentemente dos métodos em uso, a proposta considera importante a utilização de técnica visando a redução de aspectos para avaliação.

Uma questão importante para a combinação de resultados diz respeito à importância relativa ou ao peso de cada aspecto e/ou indicador na composição dos índices. Nas aproximações correntes, quando realizadas, as agregações são, normalmente, com os valores dos indicadores. Adota-se outra perspectiva: a agregação começa pelos aspectos. Isto é assim porque, afinal, qualquer ação dos agentes visa alterar o aspecto e não o indicador. A determinação da importância relativa dos aspectos dentro de cada uma das dimensões, e das dimensões por subsistema, se faz por meio de dados de avaliação dos interessados.

Para cada aspecto é identificado um indicador ou indicadores representativos. Um indicador é incluído na relação desde que satisfaça os critérios: a) representa uma questão que é essencial para o desenvolvimento sustentável; b) é mensurável quantitativa ou qualitativamente; c) é uma questão relevante para o sistema avaliado; d) está ou pode estar disponível; e e) pode ser entendido pelo público geral.

Para superar a dificuldade de medida de indicadores, adota-se uma escala chamada de escala de desempenho, desenvolvida pelo Programa das Nações Unidas para o

\section{Componentes do Método para Avaliação}

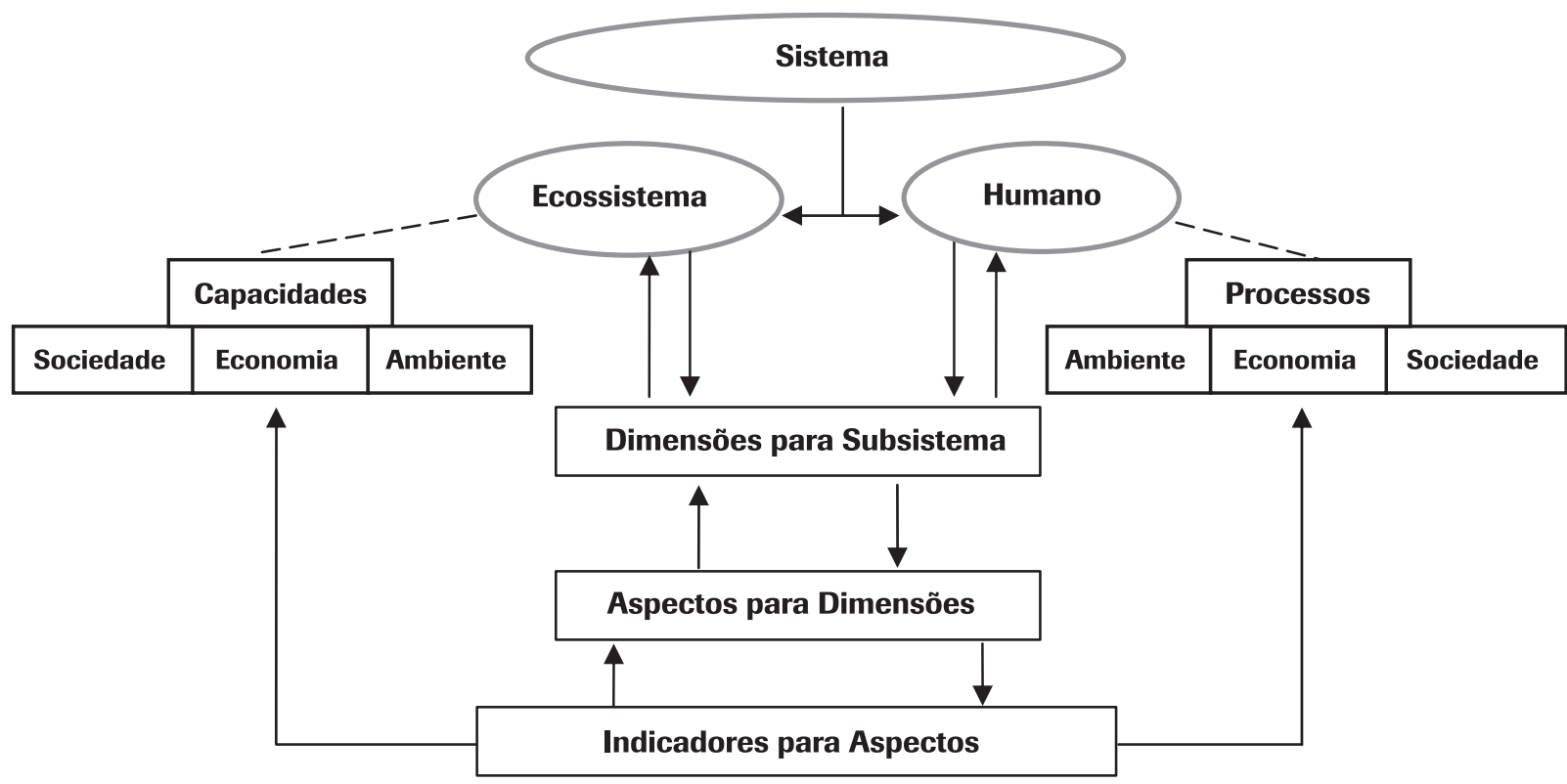

Figura 1: Componentes do Método para Avaliar Desenvolvimento Sustentável.

Fonte: Elaboração do autor. 
Desenvolvimento (UNDP, 2000) para calcular o Índice de Desenvolvimento Humano (IDH), utilizada por PrescottAllen (2001) para calcular o índice de bem-estar. Este tipo de escala valora as "coisas" de acordo com suas características próprias, permitindo empregar a medida mais adequada para o aspecto considerado.

São utilizadas duas formas de agregação. Indicadores são combinados por aspectos (se for o caso); aspectos em dimensões, dimensões em subsistemas; subsistemas em sistemas. Os indicadores também são agregados por categoria visando subsidiar o vínculo do método com o processo decisório e permitir comparações com avaliações em outros sistemas. Para agregação de dimensões em subsistemas, é adotada a técnica de consulta aos interessados sobre a importância de cada dimensão para avaliação do subsistema considerado.

O último passo da avaliação é o cálculo do índice de sustentabilidade do sistema e a apresentação dos resultados. Adotase o Barômetro de Sustentabilidade, conforme concepção de Prescott-Allen (2001), por preencher os requisitos de precisão, ser didático e simples para facilitar o entendimento e motivar ações visando ao desenvolvimento sustentável.

\section{TESTE DO MÉTODO PARA ESCOLHA E PONDERAÇÃO DE ASPECTOS E DIMENSÕES}

Para teste do método discutido foi escolhido o Estado de Rondônia. A pesquisa foi realizada nos anos de 2003 e 2004.

\subsection{Composição da Amostra}

Devido à abrangência do sistema em discussão e considerando que o principal objetivo do estudo é o processo de construção de um método, optou-se por amostra composta por especialistas: indivíduos com trabalhos de pesquisa e/ou técnicos sobre desenvolvimento, controle e fiscalização ambiental, sustentabilidade, etc., pertencentes a órgãos representativos dos seus setores atuando no Estado. Embora este fato tenha implicações sobre a extrapolação dos resultados, não compromete o teste da proposta, uma vez que a mesma é elaborada como um arcabouço que permite seu uso em diferentes níveis focais e de complexidade.

A identificação dos indivíduos foi realizada a partir dos bancos de dados das instituições e órgãos: Secretaria de Estado do Planejamento e Coordenação Geral (SEPLAD); Secretaria de Estado de Desenvolvimento Ambiental (SEDAM); Secretaria de Estado da Agricultura, Produção e do Desenvolvimento (SEAPES); Universidade Federal de Rondônia (UNIR); Em- presa Brasileira de Pesquisa Agropecuária (EMBRAPA-RO); Comissão de Pesquisa dos Recursos Minerais (CPRM); Instituto Brasileiro do Meio Ambiente e dos Recursos Renováveis (IBAMA-RO); Programa das nações Unidas para o Desenvolvimento (PNUD-RO); Plano Agropecuário e Florestal de Rondônia (PLANAFLORO); e, Fórum das Organizações Não-Governamentais (Fórum das ONGs).

\subsection{Identificação dos Aspectos Potenciais para Avaliação}

A identificação dos aspectos potenciais foi realizada por meio de consulta à literatura. Outros aspectos foram acrescentados à relação para contemplar dimensões constantes do método e geralmente não tratadas em trabalhos similares. Este último procedimento visou garantir a inclusão de aspectos específicos do sistema em foco. Foram identificados sessenta e oito (68) aspectos potenciais para as quatro dimensões, conforme Figura 2.

\subsection{Instrumentos e Coleta de Dados}

Para a escolha dos aspectos relevantes, a importância relativa de cada um e para encontrar a importância relativa de cada dimensão, as listas dos aspectos potenciais identificados na literatura e das quatro dimensões foram apresentadas aos componentes da amostra. Utilizou-se questionário de escala do tipo Likert. Os respondentes apontaram aqueles aspectos considerados de relevância para a avaliação, além de indicar outros aspectos que consideram importantes para avaliar desenvolvimento sustentável e que não constaram da relação apresentada; apontaram a ordem de importância das dimensões e destacaram os respectivos graus de relevâncias. Os questionários foram enviados por meio de correio eletrônico e o respondente teve acesso a uma página na Internet para lançar suas respostas e, ao final, remeter o questionário respondido também por meio eletrônico, sem identificação.

\subsection{Seleção dos Aspectos Relevantes e Relevâncias de Aspectos e Dimensões}

Parte-se do pressuposto que a preferência (grau de relevância ou importância relativa) total dos respondentes é a soma das preferências ou importâncias atribuídas a cada um dos aspectos. Desse modo, a preferência do conjunto dos respondentes por um dado aspecto contribui proporcionalmente para a formação do resultado da dimensão. Esta proporção é a importância relativa ou grau de relevância de cada aspecto. Apresentados os aspectos potenciais, os respondentes indicaram a relevância ou não de cada um e, numa escala de 1 a 5 , o grau de importância ou relevância para avaliar a dimensão a que pertence. A partir das respostas 
foram realizadas as análises descritivas para determinar a ponderação relativa de cada aspecto. O critério de corte para eliminar um aspecto potencial foi estabelecido como sendo a citação de não-relevância pela maioria dos respondentes (50\% mais um de citações).

\subsection{Caracterização dos Respondentes}

Ao todo foram enviados sessenta e quatro (64) questionários. Desse total, 44 (68,75\%) retornaram. Dos questioná- rios respondidos, cinco (5) não puderam ser aproveitados: questionários em branco ou apenas parcialmente respondidos. Assim, para efeito de análise foram utilizados 39 questionários respondidos, correspondendo a $60,90 \%$ do total aplicado.

Em relação ao conjunto considerado, 56,5\% trabalha ou está vinculado às organizações públicas, $48,7 \%$ está na faixa dos 36-45 e $41 \%$ na faixa dos $46-55$ anos, $43,6 \%$ possui em pós-graduação stricto sensu e 30,8\% especialização.

\begin{tabular}{|c|c|c|c|}
\hline \multicolumn{4}{|c|}{ Subsistema Humano } \\
\hline Dimensões & & Aspectos Potenciais & \\
\hline $\begin{array}{l}\text { Valores/Atitudes e } \\
\text { Organização/Poder }\end{array}$ & $\begin{array}{l}\text { - Noção (idéia ou visão) de progresso; } \\
\text { - Valores alternativos: apego à terra, à } \\
\text { tradição, etc.; } \\
\text { - Instâncias permanentes onde } \\
\text { participam setores com distintos } \\
\text { interesses; }\end{array}$ & $\begin{array}{l}\text { - Participação da sociedade } \\
\text { nas decisões sobre } \\
\text { desenvolvimento; } \\
\text { - Populações tradicionais; } \\
\text { - Populações Indígenas; } \\
\text { - Família; } \\
\text { - Legislação; }\end{array}$ & $\begin{array}{l}\text { - Governo; } \\
\text { - Grupos éticos; } \\
\text { - Direitos e liberdade; } \\
\text { - Corrupção; } \\
\text { - Crime. }\end{array}$ \\
\hline $\begin{array}{l}\text { População } \\
\text { e Saúde }\end{array}$ & $\begin{array}{l}\text { - População; } \\
\text { - População rural; } \\
\text { - Habitação; } \\
\text { - Saúde; } \\
\text { - Segurança; }\end{array}$ & $\begin{array}{l}\text { - Água potável; } \\
\text { - Qualidade da água; } \\
\text { - Gênero; } \\
\text { - Fertilidade; } \\
\text { - Infância; }\end{array}$ & $\begin{array}{l}\text { - Pobreza; } \\
\text { - Alimentação; } \\
\text { - Saneamento; } \\
\text { - Acidentes; } \\
\text { - Desenvolvimento } \\
\text { humano. }\end{array}$ \\
\hline $\begin{array}{l}\text { Conhecimento } \\
\text { e Cultura }\end{array}$ & $\begin{array}{l}\text { - Estágio do Conhecimento; } \\
\text { - Infra-estrutura de comunicação; } \\
\text { - Arte e cultura; } \\
\text { - Acesso a Informação }\end{array}$ & $\begin{array}{l}\text { - Investimentos em pesquisa e } \\
\text { desenvolvimento; } \\
\text { - Nível de conhecimento dos } \\
\text { problemas ambientais; }\end{array}$ & $\begin{array}{l}\text { - Limitações para } \\
\text { mudança; } \\
\text { - Educação. }\end{array}$ \\
\hline $\begin{array}{l}\text { Riqueza } \\
\text { e renda }\end{array}$ & $\begin{array}{l}\text { - Emprego; } \\
\text { - Eqüidade; } \\
\text { - Renda Per Capita; }\end{array}$ & $\begin{array}{l}\text { - Crescimento econômico; } \\
\text { - Investimentos Sociais; }\end{array}$ & $\begin{array}{l}\text { - Produtividade; } \\
\text { - Produção de Alimentos. }\end{array}$ \\
\hline \multicolumn{4}{|c|}{ Subsistema Ecossistema } \\
\hline Dimensões & & Aspectos Potenciais & \\
\hline $\begin{array}{l}\text { Manutenção da } \\
\text { Biodiversidade }\end{array}$ & $\begin{array}{l}\text { - Ecossistemas naturais e } \\
\text { transformados; }\end{array}$ & $\begin{array}{l}\text { - Proteção de amostras } \\
\text { representativas de } \\
\text { ecossistemas naturais; }\end{array}$ & $\begin{array}{l}\text { - Recursos pesqueiros; } \\
\text { - Áreas protegidas. }\end{array}$ \\
\hline $\begin{array}{l}\text { Solo, Floresta } \\
\text { e Água }\end{array}$ & $\begin{array}{l}\text { - Erosão do solo; } \\
\text { - Esgotamento do solo; } \\
\text { - Desmatamento; }\end{array}$ & $\begin{array}{l}\text { - Queimadas; } \\
\text { - Ar; } \\
\text { - Mata ciliar; }\end{array}$ & $\begin{array}{l}\text { - Desertificação; } \\
\text { - Fertilizantes e } \\
\text { pesticidas agrícolas. }\end{array}$ \\
\hline $\begin{array}{l}\text { Espécies e } \\
\text { População }\end{array}$ & - Diversidade nas espécies; & - Espécies exóticas; & $\begin{array}{l}\text { - } \text { Diversidade da } \\
\text { população; } \\
\text { - Risco de extinção. }\end{array}$ \\
\hline $\begin{array}{l}\text { Uso dos } \\
\text { Recursos }\end{array}$ & $\begin{array}{l}\text { - Recursos renováveis; } \\
\text { - Recursos não-renováveis; } \\
\text { - Reciclagem; }\end{array}$ & $\begin{array}{l}\text { - Materiais; } \\
\text { - Energia; } \\
\text { - Terra; }\end{array}$ & $\begin{array}{l}\text { - Água; } \\
\text { - Geração de } \\
\text { desperdícios; } \\
\text { - Resíduos sólidos. }\end{array}$ \\
\hline
\end{tabular}

Figura 2: Aspectos Potenciais para Avaliação da Sustentabilidade.

Fonte: Elaboração do autor. 


\subsection{Aspectos Relevantes e Grau de Relevância}

Pelo critério de corte adotado, constatou-se que todos os aspectos relacionados, 68 ao todo, foram considerados relevantes para avaliar a sustentabilidade das dimensões. Este resultado pode indicar a adequação da relação dos aspectos potenciais ou a dificuldade dos respondentes em identificar um grupo menor de aspectos. Este resultado trouxe dificuldades adicionais para a avaliação devido ao elevado número de aspectos por dimensões, o que ensejou uma análise fatorial para redução do número de aspectos.

\subsection{Ponderação dos Aspectos Relevantes}

Os procedimentos adotados para análise dos dados para os aspectos da dimensão "Valores/Atitudes e Organização/ Poder", detalhados a seguir, são os mesmos para as demais dimensões.

Para esta dimensão, observou-se que a importância dos aspectos varia de aproximadamente $6 \%$ a $8,9 \%$, indicando que, na visão dos respondentes, todos os aspectos possuem relevâncias que se aproximam. Considerando esta tendência à "homogeneização", realizou-se um teste de médias para verificar a ocorrência de diferenças. O fato de vários aspectos receberem médias que não são diferentes pode significar que os respondentes atribuem-lhes aproximadamente a mesma importância ou que são percebidos como representando preocupações semelhantes. Aspectos potenciais apresentados podem ser entendidos como representando (e de fato representam) preocupações semelhantes. A não eliminação de aspectos potenciais e a pequena ocorrência de diferenças entre médias ensejaram a realização de testes visando reduzir o número de aspectos a serem considerados na avaliação. A técnica escolhida para este fim foi a análise fatorial.

A adoção da técnica foi numa perspectiva mais exploratória. $\mathrm{O}$ fato de um subconjunto de aspectos ser congregado em determinado fator não significa substituição automática por este. Quando necessário, o subconjunto foi dividido ou foram formados outros subconjuntos de acordo com a análise fatorial e os significados dos aspectos.

Foram realizados testes para verificar a adequação do uso da análise fatorial (análise de correlação e a medida de Kaiser-Meyer-Olkin-KMO). Os testes indicaram que há um número considerável de variáveis fortemente correlacionadas entre si. O teste de esfericidade informou que poucos fatores poderiam explicar a grande proporção da variabilidade dos dados. Assim, os resultados indicaram que a aplicação da análise fatorial é adequada para o caso em tela. A extração dos fatores foi realizada através do método dos principais componentes.

Os dados indicaram que, a partir do quinto ou sexto fator, os autovalores apresentam um baixo poder explicativo. $\mathrm{Na}$ Tabela 1 estão as cargas fatoriais que indicam o peso de cada um dos cinco principais fatores.

Constata-se que a maioria das variáveis é explicada, prin-

Tabela 1: Matriz de Componentes.

\begin{tabular}{|c|c|c|c|c|c|}
\hline \multirow{2}{*}{ Aspectos } & \multicolumn{5}{|c|}{ Componentes (Fatores) } \\
\hline & 1 & 2 & 3 & 4 & 5 \\
\hline ASP 1 & 0,845 & 0,220 & 0,114 & 0,181 & $-0,156$ \\
\hline ASP 2 & 0,916 & $-0,033$ & $-0,029$ & $-0,218$ & $-0,248$ \\
\hline ASP 3 & 0,345 & 0.050 & 0,920 & $-0,038$ & 0,012 \\
\hline ASP 4 & 0,847 & 0,025 & 0,061 & 0,042 & $-0,313$ \\
\hline ASP 5 & 0,941 & 0,016 & $-0,047$ & $-0,106$ & 0,178 \\
\hline ASP 6 & 0,918 & $-0,061$ & $-0,034$ & $-0,001$ & 0,200 \\
\hline ASP 7 & 0,637 & 0,645 & $-0,129$ & 0,015 & 0,221 \\
\hline ASP 8 & 0,530 & 0,622 & 0,187 & 0,198 & 0,277 \\
\hline ASP 9 & 0,626 & 0,124 & $-0,055$ & 0,724 & 0,032 \\
\hline ASP 10 & 0,768 & $-0,008$ & 0,033 & 0,051 & 0,567 \\
\hline ASP 11 & 0,805 & 0,251 & 0,387 & 0,135 & $-0,059$ \\
\hline ASP 12 & 0,176 & 0,879 & 0,019 & 0,225 & $-0,127$ \\
\hline ASP 13 & 0,113 & 0,905 & 0,016 & $-0,238$ & $-0,037$ \\
\hline
\end{tabular}

Fonte: Elaboração do autor. 
cipalmente, por um único fator. Por exemplo, o ASP 1 (aspecto 1) é explicado, principalmente, pelo fator 1 . Analisando os dados da perspectiva estritamente matemática, poderiam ser extraídas quatro varáveis (fatores) subjacentes: variável A, substituindo os aspectos ASP 1, 2, 4, 5, 6, 10 e 11; variável B, os aspectos ASP 7, 8, 12, e 13; variável C, o aspecto ASP 3, e variável $\mathbf{D}$ o aspecto ASP 9. Esta conseqüência não parece adequada para aplicação direta ao problema em discussão por duas razões: as varáveis subjacentes podem se referir a aspectos para os quais não há evidências de que possam ser medidos pelas mesmas características, sugerindo que representam preocupações diferentes; uma variável subjacente pode representar um conjunto muito grande de aspectos, o que impede a avaliação de preocupações específicas. Assim, um conjunto de aspectos explicados por um fator pode ser dividido em dois ou mais subconjuntos.

Cotejando os resultados da análise fatorial com a relação de aspectos e seus significados para avaliação, é realizada a redução do número de aspectos para a referida dimensão e refeito o procedimento para o cálculo da importância relativa. Para tanto, trabalhou-se com a soma das importâncias atribuídas pelos respondentes aos aspectos originais. Este mesmo procedimento foi utilizado para outras dimensões.

\subsection{Síntese dos Resultados das Análises para Relevância dos Aspectos e Dimensões com Base na Consulta aos Especialistas}

Como resultado geral das análises realizadas, chegou-se à configuração de 28 (vinte oito) aspectos, 17 (dezessete) destes para o subsistema humano e 11 (onze) para o ecossistema, com as respectivas ponderações, conforme Tabela 2.

Para o subsistema humano, os testes para Comparações Múltiplas de Tukey-Kramer dos dados sobre a relevância demonstraram que a média dos valores atribuídos para a dimensão população e saúde difere das médias das outras dimensões do subsistema humano. Em relação aos aspectos desta dimensão, os respondentes apontaram como mais relevante o aspecto saúde e saneamento. Há também diferença entre as médias para as dimensões riqueza e renda e conhecimento e cultura. Quanto aos outros pares, não se pode afirmar que diferem.

As análises dos dados para as dimensões do Ecossistema sugerem que, na visão dos respondentes, as preocupações relativas ao desmatamento e queimadas da dimensão solo, floresta e água, devem receber prioridade para avaliação. $\mathrm{O}$ teste com os dados sobre o grau de relevância demonstrou que a média dos valores atribuídos para esta dimensão difere das médias de outras duas dimensões, Manutenção da Biodiversidade e Espécies e População.

\subsection{TESTE DO MÉTODO PARA CÁLCULO DE INDICADORES E AGREGAÇÃO DOS DADOS}

Tendo como referência o resultado da consulta aos especialistas para realizar a agregação dos dados, foram selecionados e calculados os indicadores e índices para o estado de Rondônia, conforme descrito a seguir.

\subsection{Identificação e Medida dos Indicadores}

A escolha dos indicadores pode ser realizada de várias formas, não necessariamente excludentes: consulta aos grupos de interesse ou tomadores de decisão; indicadores citados na literatura (especialistas); desenvolvidos pela equipe de avaliação, etc. Neste trabalho, faz-se a opção por indicadores citados na literatura. Quando mais de um indicador é identificado para um determinado aspecto, recomenda-se consultar os grupos de interesse para estabelecer o peso de cada um para a combinação dos dados. Quando esse procedimento não for possível, pode ser utilizado critério da média aritmética ou média ponderada de acordo com critérios do analista ou equipe de avaliação. Neste trabalho adotou-se a média aritmética.

Ao todo foram identificados e mensurados 44 (quarenta e quatro) indicadores, para o conjunto de aspectos relevantes, cujos valores foram transformados para uma mesma escala para possibilitar agregação dos dados. Para tanto, utilizouse uma escala de desempenho, o que permitiu expressar os valores dos indicadores na mesma unidade de medida.

Os valores encontrados para os 44 (quarenta e quatro) indicadores estão na Tabela 3.

A Escala adotada é do tipo que possui definição de dois extremos: melhor e pior desempenho e as características: base 0 (zero) e topo cem (100); 0 (zero) é base da banda ruim (insustentável); 20: topo da banda ruim e base da banda pobre (quase insustentável); 40: topo da banda pobre e base da banda intermediária; 60: topo da banda intermediária e base da banda aceitável (quase sustentável); 80: topo da banda aceitável e base da banda boa (sustentável); e, 100: topo da banda sustentável. Quanto aos critérios para seleção dos valores das bandas ou faixas da escala de desempenho, são definidos da forma seguinte: 1 . um intervalo de desempenho onde, em geral, os extremos são 0 e 100; 2 o objetivo do aspecto em referência; 3 . pelo menos um dos seguintes critérios: taxa sustentável estimada; desempenho esperado; padrão nacional ou internacional; objetivo; opinião de especialistas; derivada de um indicador relacionado; e julgamento pessoal.

Em relação aos critérios de desempenho, os indicadores podem ser classificados em cinco grupos ou tipos: 1 . melhor desempenho é 0 (zero), $100 \%$ ou paridade; 2 . sem limite 
Siena, O. Método para avaliar desenvolvimento sustentável: técnicas para escolha e ponderação de aspectos e dimensões. Produção, v. 18, n. 2, p. 359-374, 2008.

Tabela 2: Síntese dos Dados sobre a Relevância dos Aspectos e Dimensões.

\begin{tabular}{|c|c|c|c|}
\hline Subsistema & Dimensões & Aspectos & Ponderação (Relevância) \\
\hline \multirow[t]{21}{*}{ Humano } & Valores/Atitudes e Organização/Poder & & 0,225 \\
\hline & & Valores & 0,421 \\
\hline & & Organização e Poder & 0,336 \\
\hline & & Homicídios & 0,081 \\
\hline & & Corrupção & 0,088 \\
\hline & & Instâncias Negociações & 0,074 \\
\hline & População Saúde & & 0,302 \\
\hline & & População & 0,213 \\
\hline & & Saúde e Saneamento & 0,402 \\
\hline & & Segurança & 0,152 \\
\hline & & Gênero & 0,061 \\
\hline & & Pobreza e Infância & 0,172 \\
\hline & Conhecimento Cultura & & 0,218 \\
\hline & & Conhecimento Pesquisa & 0,482 \\
\hline & & Educação & 0,161 \\
\hline & & Informação e Cultura & 0,357 \\
\hline & Riqueza Renda & & 0,255 \\
\hline & & Emprego Renda & 0,307 \\
\hline & & Desenvolvimento Econômico & 0,401 \\
\hline & & Investimentos Sociais & 0,151 \\
\hline & & Eqüidade & 0,141 \\
\hline \multirow[t]{15}{*}{ Ecossistema } & Manutenção da Biodiversidade & & 0,229 \\
\hline & & Áreas Protegidas & 0,798 \\
\hline & & Recursos Pesqueiros & 0,202 \\
\hline & Solo, Floresta e Água & & 0,285 \\
\hline & & Solo & 0,354 \\
\hline & & Desmatamento e Queimadas & 0,529 \\
\hline & & Contaminação & 0,117 \\
\hline & Espécies e População (Gene) & & 0,224 \\
\hline & & Diversidade Vegetal & 0,407 \\
\hline & & Diversidade Animal & 0,391 \\
\hline & & Espécies Alienígenas & 0,202 \\
\hline & Uso dos Recursos & & 0,262 \\
\hline & & Recursos Renováveis & 0,389 \\
\hline & & Recursos Não-Renováveis & 0,258 \\
\hline & & Materiais e Energia & 0,353 \\
\hline
\end{tabular}


para o melhor desempenho possível, mas o limite para o pior possível é 0 (zero) ou 100\%; 3. definição de nível sustentável, fora do qual as condições são insustentáveis; 4 . nível sustentável definido somente em um extremo, além da qual as condições são insustentáveis; 5 . desempenho bom e ruim claramente definido, mas sem definição do melhor, do pior ou do nível sustentável.

\subsection{Agregação dos Dados}

A agregação se tornou possível porque todas as medidas para os indicadores foram transformadas em escores utilizando uma mesma escala de desempenho. Das agregações previstas duas não contemplam a adoção da ponderação: o índice de cada aspecto corresponde à média aritmética dos escores dos indicadores. O mesmo procedimento é adotado para combinação dos resultados dos indicadores em subca- tegorias, e de subcategorias em categorias. Para agregação dos índices de aspectos em dimensões e dimensões em subsistemas, são adotados os fatores de ponderação obtidos com os resultados da consulta aos especialistas. A agregação dos índices de subsistemas em sistemas é realizada diretamente, pois se considera que os subsistemas são igualmente importantes.

O resultado da organização dos indicadores em subcategorias e categorias, os escores e os índices resultantes das agregações dos dados estão dispostos na Tabela 4.

Este tipo de agregação serve a três propósitos básicos. O primeiro é facilitar a vinculação do método com o processo de tomada de decisões; a obtenção de índices para as subcategorias, divisão tradicionalmente utilizada no processo de planejamento e nas discussões políticas, possibilita uma análise compreensiva por técnicos e políticos.

Tabela 3: Relação dos Indicadores e Respectivos Escores.

\begin{tabular}{lc}
\hline \multicolumn{1}{c}{ Indicadores } & $\begin{array}{c}\text { Escores } \\
\text { (de 0 a 100) }\end{array}$ \\
\hline Extinção Línguas Indígenas & 16,0 \\
Liberdade: Civil, Política e de Imprensa & 56,0 \\
Instâncias Permanentes Negociação & 85,7 \\
Fertilidade Total & 61,0 \\
Crescimento Populacional & 53,5 \\
Pessoal em Pesquisa & 21,4 \\
Investimento em Pesquisa & 1,2 \\
Investimentos Sociais & 19,5 \\
PIB Per Capita & 38,0 \\
Investimento em Cultura & 4,7 \\
Áreas de Proteção Integral & 45,2 \\
Áreas de Uso Sustentável & 69,0 \\
Produção Bruta de Recursos Renováveis & 46,1 \\
Produção Bruta de Recursos Não-Renováveis & 61,7 \\
Participação das Populações Tradicionais nas & 14,3 \\
Decisões & 40,0 \\
Corrupção Percebida & 37,3 \\
Homicídios & 48,0 \\
Participação Sociedade nas Decisões & 49,8 \\
Expectativa de Vida Saudável & 12,6 \\
Acesso a Rede de Água e Esgoto & 40,8 \\
Malária & 23,6 \\
Segurança Pública & \\
\hline Fonte:Elaboracão do autor. & \\
\hline &
\end{tabular}

\begin{tabular}{lc}
\hline \multicolumn{1}{c}{ Indicadores } & $\begin{array}{c}\text { Escores } \\
\text { (de 0 a 100) }\end{array}$ \\
\hline Gênero: Participação no Mercado de Trabalho & 79,3 \\
Gênero: Razão de Renda & 70,0 \\
Gênero: Participação Política & 4,4 \\
Mortalidade Infantil & 48,4 \\
População em Estado de Pobreza & 47,8 \\
Atendimento Escolar de Crianças e Jovens & 57,8 \\
Atendimento Escolar: Ensino Superior & 20,7 \\
Recursos de Cultura & 10,4 \\
Linhas de Telefone e Acesso a Internet & 38,5 \\
Acesso a Televisão por Assinatura & 33,4 \\
Desemprego & 43,6 \\
PIB Per Capita & 38,0 \\
Índice Gini de Renda & 42,2 \\
Desigualdade de Renda entre Classes & 19,5 \\
Extremas & \\
Consumo de Energia Per Capita & 97,7 \\
Erosão do Solo & 29,5 \\
Contaminação por Mercúrio & 57,2 \\
Desmatamento & 15,5 \\
Queimadas & 55,2 \\
Extrativismo Vegetal & 74,4 \\
Uso de Fertilizantes e Praguicidas & 53,6 \\
Geração de Desperdícios & \\
\hline
\end{tabular}

Fonte: Elaboração do autor. 
Tabela 4: Combinação de resultados de acordo com as categorias.

\begin{tabular}{lc}
\hline \multicolumn{2}{c}{ Índices de Sustentabilidade para Categorias e Subcategorias } \\
\hline Categorias & Índices (0 a 100) \\
Recursos ou Capacidades e Desafios & 40,1 \\
Processos e Resultados & 44,1 \\
Subcategorias & Índices (0 a 100) \\
Social & 43,4 \\
Econômica & 30,3 \\
Ambiental & 52,7 \\
Subsistema & Índices (0 a 100) \\
Humano & 36,7 \\
Ecossistema & 52,7 \\
\hline
\end{tabular}

Fonte: Elaboração do autor.

Outro propósito é permitir a comparação com os resultados encontrados com base na agregação por aspectos e dimensões. A combinação dos resultados para categorias, embora tenha sido realizada por agregação simples dos escores dos indicadores e sem qualquer tipo de ponderação, possui uma vinculação com o método, uma vez que os indicadores foram identificados para os aspectos considerados relevantes.

A figura 3 apresenta o diagrama com os índices de sustentabilidade do Subsistema Humano e suas Dimensões.
De acordo com os resultados do teste da abordagem proposta neste trabalho, o valor do índice de sustentabilidade para o subsistema humano, de 35,28 coloca o estado de Rondônia numa faixa de desenvolvimento quase insustentável. A maior contribuição negativa para composição desse valor vem da dimensão conhecimento e cultura, localizada numa situação insustentável, embora nenhuma das dimensões tenha alcançado índice considerado aceitável em termos de sustentabilidade.

Em relação ao Subsistema Ecossistema, conforme dados da Figura 4, o índice obtido foi de 56,35 situando o estado de Rondônia numa região de sustentabilidade média, numa escala de zero a cem.

Das quatro dimensões deste subsistema, uma se situa na faixa intermediária, duas com desempenho aceitável e uma, Solo, Floresta e Água, com desempenho abaixo da média. Em relação a esta última - que contempla questões como desmatamento e erosão do solo - deve merecer atenção, considerando que ela pode, a médio e longo prazos, piorar os desempenhos das outras dimensões. Uma outra preocupação é o fato de o índice para este subsistema ter sido influenciado pelo bom desempenho da dimensão população (gene) e espécies, para a qual não se pode contar com dados sobre diversidade animal e espécies exóticas.

$\mathrm{O}$ índice de sustentabilidade para um sistema, de acordo com a concepção adotada neste trabalho, tem como hipótese subjacente que o desenvolvimento sustentável é uma combinação do bem-estar humano e do ecossistema; o primeiro é

\section{Subsistema Humano}

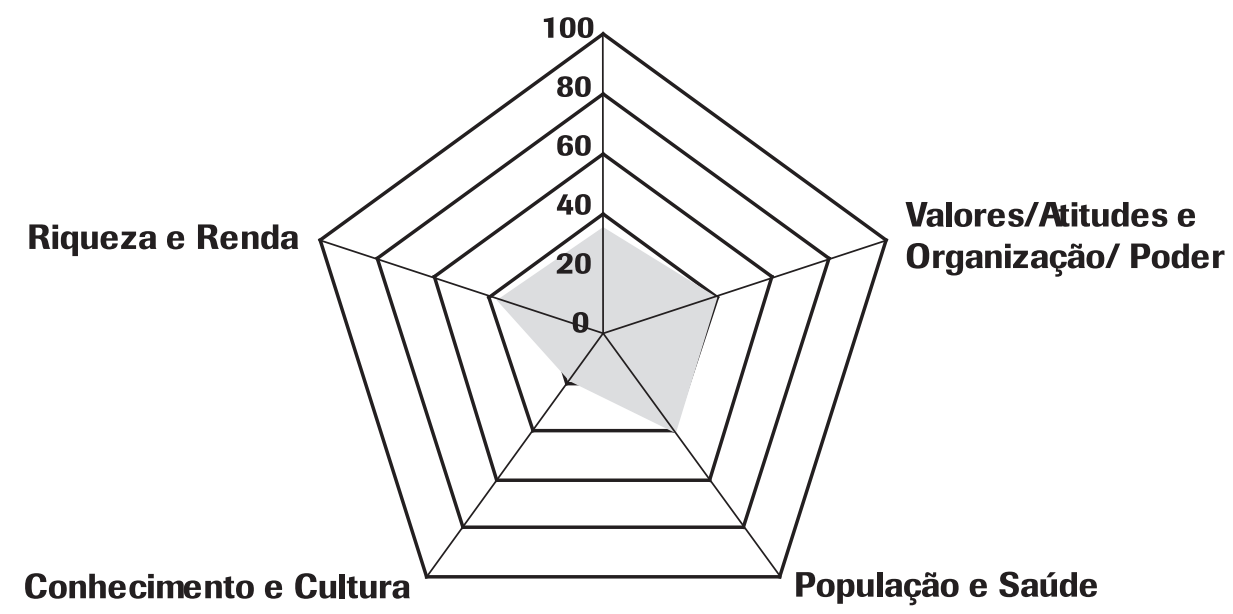

Figura 3: Índice de Sustentabilidade do Subsistema Humano.

Fonte: Elaboração do autor. 
um requerimento para a sustentabilidade porque nenhuma pessoa racional gostaria de perpetuar um baixo padrão de vida; o segundo é requerimento para a sustentabilidade porque é o ecossistema que suporta e torna possível algum padrão de vida. Nesta perspectiva, a sustentabilidade das pessoas e do ecossistema deve ser considerada mais em conjunto que em separado; não pode haver sustentabilidade se um deles estiver em situação insustentável. De acordo com este entendimento e para efeito de teste do método discutido, foi determinado o índice de Sustentabilidade para o estado de Rondônia. As Figuras 5 e 6 apresentam duas possíveis representações para o referido índice.

A primeira representação, ilustrada pelo diagrama de radar da Figura 5, considerando os resultados do teste da

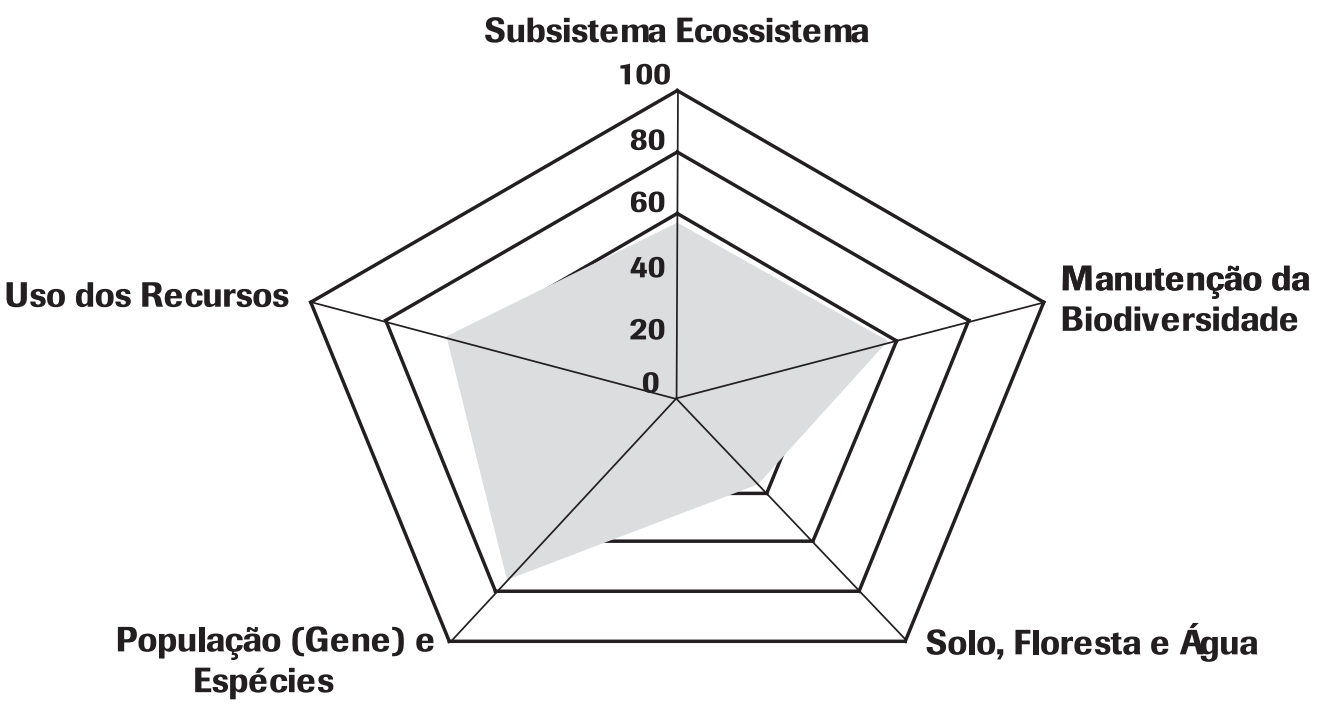

Figura 4: Índice de Sustentabilidade do Subsistema Ecossistema.

Fonte: Elaboração do autor.

\section{Subsistema Ecossistema}

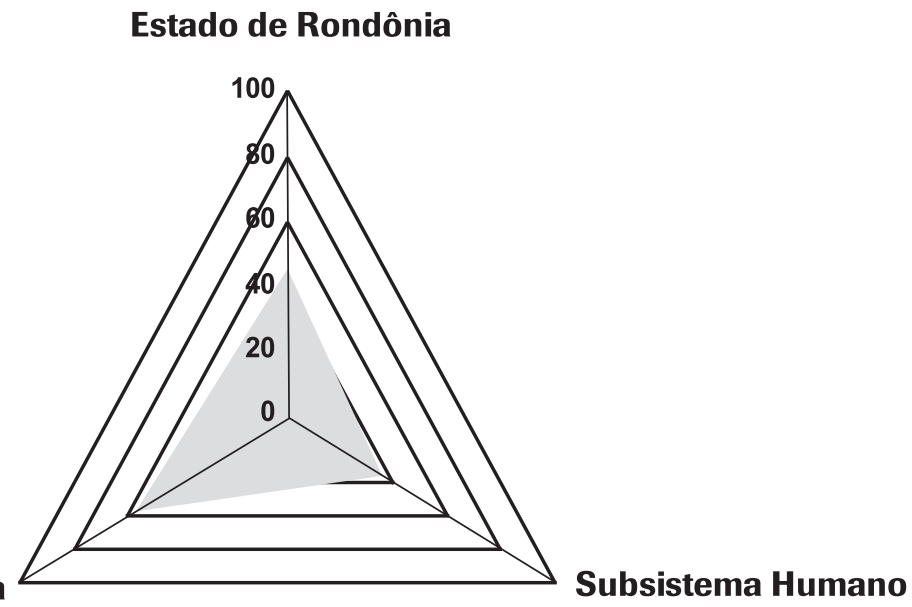

Figura 5: Índice de Sustentabilidade do Estado de Rondônia.

Fonte: Elaboração do autor. 
abordagem aqui discutida, permite dizer que Rondônia possui um desempenho geral considerado de média sustentabilidade, sendo o desempenho do subsistema humano quase insustentável e do ecossistema medianamente sustentável. O valor de 45,82 foi encontrado pela média simples dos índices dos subsistemas humano e ecossistemas, considerando-os como igualmente importantes.

A segunda representação, ilustrada pelo Barômetro de Sustentabilidade, que é uma forma de apresentação sugerida por Prescott-Allen (1997; 2001), Figura 6, é coerente com o método para avaliar sustentabilidade discutido neste trabalho. Na referida figura, as esferas verticais ilustram a locali- zação dos índices para as dimensões do subsistema humano; as esferas horizontais representam a localização dos índices das dimensões do subsistema ecossistema. A localização do estágio do desenvolvimento de Rondônia é determinada pela intersecção de duas retas imaginárias a partir dos desempenhos dos dois subsistemas. Considerando os resultados do teste da abordagem discutida neste trabalho, os resultados informam que o desempenho geral do estado de Rondônia se localiza na área identificada como Quase Insustentabilidade. Esta é a interpretação adotada como resultado da avaliação do atual estágio do desenvolvimento sustentável do Estado de Rondônia.

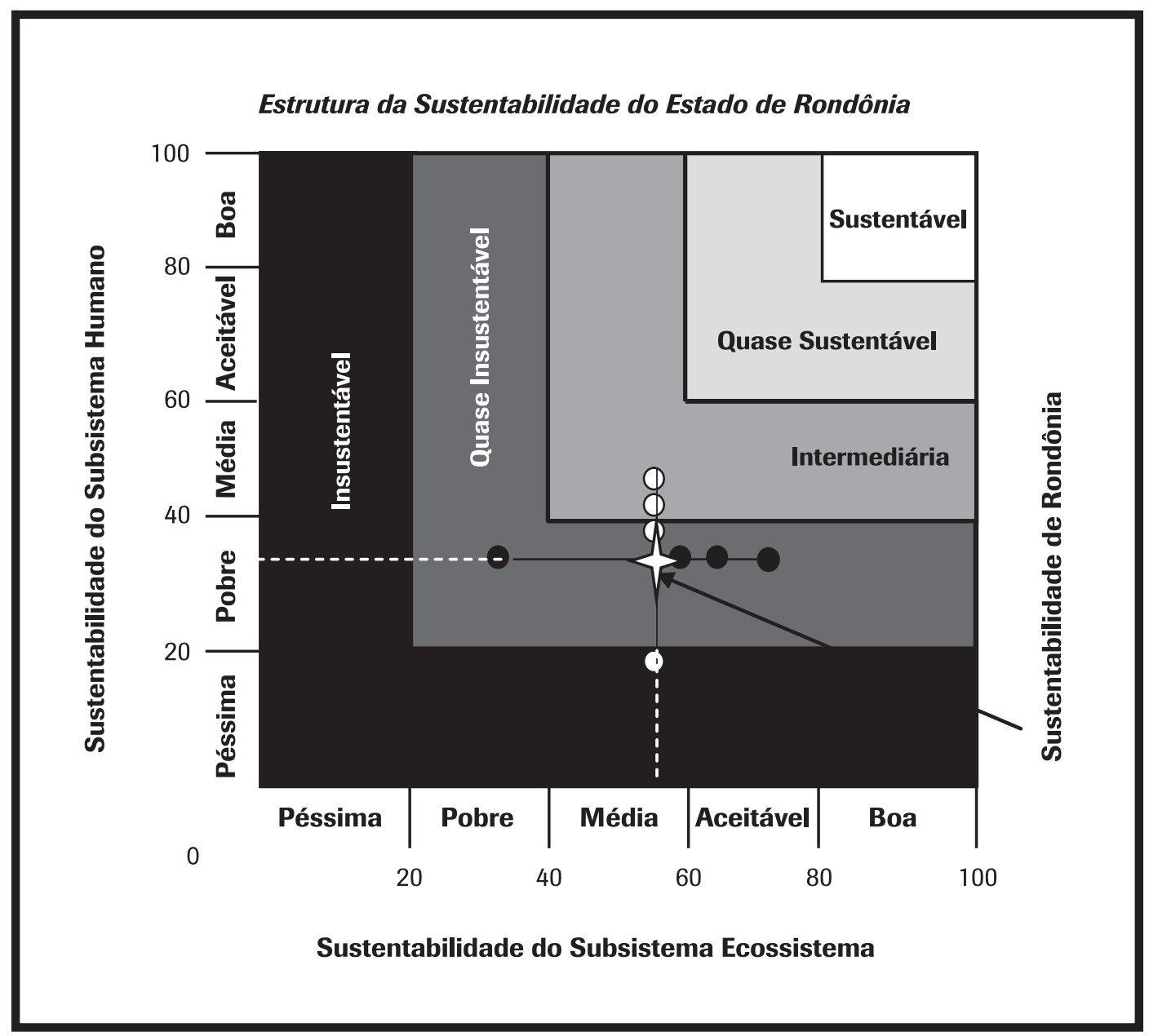

Figura 6: Índice de Desenvolvimento Sustentável do Estado de Rondônia.

Fonte: Elaboração do autor com base nos resultados da pesquisa, utilizando o Barômetro de Sustentabilidade, instrumento proposto por Prescott-Allen (1997; 2001) para apresentação dos índices. 


\section{CONCLUSÕES}

Os problemas ambientais como o desmatamento, degradação da terra e contaminação parecem fazer parte da história humana. Entretanto, o agravamento das dificuldades sociais e ecológicas é também conseqüência do modelo industrial que incentiva uma sociedade cada vez mais consumista. As discussões sobre desenvolvimento sustentável se inserem neste contexto e todos, ou quase todos, dizem que o almejam, embora pouco ainda se saiba o que significa sustentabilidade para uma dada sociedade. Parece ser consenso, no entanto, que não haverá desenvolvimento sustentável se ele não for almejado. É necessário que a sociedade decida qual a sustentabilidade desejada e adote decisões e ações nessa direção.

Esse debate sobre a sustentabilidade da relação da sociedade e ambiente passou a fazer parte da agenda de governos e de setores influentes da sociedade. Há movimentação significativa de indivíduos e de organizações e agências nacionais e internacionais. Embora se reconheça que essa movimentação é fundamental, há muito por fazer em relação à operacionalização do conceito.

Neste trabalho, foi discutida uma forma de operacionalização da avaliação da sustentabilidade que demonstra um bom grau de atendimento aos Princípios Bellagio para avaliar Sustentabilidade. Isto sugere que os procedimentos adotados são promissores, embora se reconheça que a abordagem necessita de testes em outros níveis focais e refinamentos quanto aos materiais e métodos adotados.

O método discutido testou técnicas para escolha e ponderação dos aspectos e dimensões, bem como para redução do número de aspectos e, por conseqüência, do número de indicadores para avaliação. Os procedimentos e técnicas utilizados apontam para a possibilidade de superar lacunas e para o aprimoramento das aproximações vigentes em relação às questões consideradas.

Foi realizado um teste do método discutido tendo como foco o Estado de Rondônia.

A identificação dos aspectos potenciais foi realizada por meio de consulta à literatura. Foram identificados 68 (sessenta e oito) aspectos potenciais, agrupados por dimensões. A consulta a atores chaves do sistema em foco precedeu a escolha e ponderação dos aspectos e pondera- ção das dimensões. Testou-se a utilização da análise fatorial para redução do número de aspectos para avaliação. Como resultado geral, chegou-se à configuração de 28 (vinte oito) aspectos, e suas respectivas ponderações, 17 (dezessete) destes para o subsistema humano e 11 (onze) para o ecossistema.

Para o subsistema humano, os dados sobre a relevância demonstraram maior importância atribuída à dimensão população e saúde. Em relação aos aspectos desta dimensão, os respondentes apontaram como mais relevante o aspecto saúde e saneamento. As análises dos dados para as dimensões do Ecossistema indicaram maior relevância para desmatamento e queimadas da dimensão solo, floresta e água.

\section{hegou-se à configuração de 28 (vinte e} subsistema humano e 11 (onze) para o ecossistema.
Tendo como referência o resultado da consulta aos especialistas para realizar a agregação dos dados, foram selecionados e calculados os indicadores e índices para o estado de Rondônia.

De acordo os resultados do teste da abordagem discutida neste trabalho, o valor do índice de sustentabilidade para o subsistema humano coloca o estado de Rondônia numa faixa de baixa sustentabilidade, de acordo com os critérios adotados. A maior contribuição negativa para composição desse valor vem da dimensão conhecimento e cultura, localizada numa sustentabilidade muito baixa, embora nenhuma das dimensões tenha alcançado índice considerado aceitável em termos de sustentabilidade.

Em relação ao Subsistema Ecossistema, o índice obtido situa o estado de Rondônia numa região de sustentabilidade média, numa escala de zero a cem. Das quatro dimensões deste subsistema, uma se situa na faixa intermediária, duas com desempenho aceitável e uma, Solo, Floresta e Água, com desempenho abaixo da média.

Considerando os resultados do teste da abordagem discutida neste trabalho e tendo em vista os critérios adotados, os resultados informam que o desempenho geral do estado de Rondônia se localiza numa faixa de baixa sustentabilidade. 


\section{REFERÊNCIAS}

AGENDA 21. Conferência das Nações Unidas sobre Meio Ambiente e Desenvolvimento. Brasília: Câmara dos Deputados, 1995.

BELLEN, H. M. V. Indicadores de sustentabilidade: uma análise comparativa. Rio de Janeiro: FGV, 2005.

BOSSEL, H. Indicators for sustainable development: theory, method, applications. Winnipeg: International Institute for Sustainable Development, 1999.

COBB, C. et al. The genuine Progress Indicators: summary of data and methodology. San Francisco: Redefining Progress, 1995.

CUSTANCE, J.; HILLIER, H. Statistical issues in indicators of sustainable development. Journal of the Royal Statistical Society, 161: Pat. 3, p. 281-290, 1998.

HARDI, P. et al. Measuring sustainable development. review of current practice. Occasional Paper Number 17. Canada: Industry Canada, 1997.

HARDI, P.; ZDAN, T. (eds.). Assessing sustainable development: principles in practice. Canada: International Institute for Sustainable Development, 1997.

HODGE, R. A.; HARDI, P.; BELL, D. V. J. Seeing change through the lens of sustainability. Costa Rica: 1999. Disponível em: $<$ http://iisd.ca/measure/scipol/docs.htm>. Acessado em: 4 dez. 2000.

HODGE, R. A. Assessing progress toward sustainability: development of a systemic framework and reporting structure. Ph.D. (interdisciplinary) Dissertation. School of Urban Planning, Faculty of Engineering, McGill University. Montreal, 1995.

IBGE - Instituto Brasileiro de Geografia e Estatística. IDS: indicadores de desenvolvimento sustentável. Brasil: IBGE, 2004. Disponível em <http://www.ibge.gov.br/home/geociencias/recursosnaturais/ids/defaulttab.shtm $>$. Acessado em 25 nov. 2007.
IISD - International Institute for Sustainable Development. Aggregated indices. Canada: 1999 e 2005. Disponível em <http://iisd.ca/ cgsddi/indeices.htm>.

IMBACH, et al. Mapeo analítico, reflexivo y participativo de la sostenibilidad - MARPS. UICN, 1997.

Bellagio Principles. Disponível em: $<$ http://iisd.ca/measure/1.thm $>$. Acessado em: 22 mar. 2001.

IWGSDI. Interagency Working Group on Sustainable Development Indicators. Sustainable development in the Unites States - an experimental set of indicators. Washington, 1998. Disponível em: <http://sdi.gov/iwgsdi.htm>. Acessado em 4 dez. 2000.

Interagency Working Group on Sustainable Development Indicators. Sustainable development in the Unites States - an experimental set of indicators. Washington, 2001. Disponível em: <http://sdi.gov/iwgsdi.htm >. Acessado em 15 out. 2001.

JACOBS, M. The green economy: environment, sustainable development, and the politics of future. Vancouver: UBC Press, 1993.

KELLY, K. L. A systems approach to identifying decisive information for sustainable development. EJOR, 109: 452-464, 1998

MEADOWS, D. Indicators and information systems for sustainable development. The Sustainability Institute, 1998.

MOLDAN, B.; BILLHARZ, S.; MATRAVERS, R (Ed.). Sustainability indicators: a report on the project on indicators of sustainable development (SCOPE 58). New York : John Wiley, 1997.

OECD. Environmental performance reviews: a practical introduction. Paris: OECD, 1997.

To measure sustainable development. Paris: OECD, 2000.
PRESCOTT-ALLEN, R. Barómetro de la sostenibilidad: medición y comunicación del bienestar y el desarrollo sostenible. UICN, 1997.

Assessing progress toward sustainability: the system assessment meted illustrated by the wellbeing of nations. UICN, 1999.

The wellbeing of nations: a country-bycountry index of quality of life and environment. Washington: Island Press, 2001.

TIETENBERG, T. Environmental and natural resource economics. 3. ed. New York: Harper Collins, 1992

UNCSD. United Nations. Commission on Sustainable Development. Indicators of sustainable development. New York: UN CSD, 1996.

Development Human Report 2000. UNDP, 2001. Disponível em: <http://www. undp.org.br/hdr/hdr2000>. Acessado em: 25 mar. 2001.

United Nations. Division for Sustainable Development. Indicators of sustainable development. guidelines and methodologies. New York, 2001.

Report on the aggregation of indicators of sustainable development: background paper for Ninth Session of the Commission on Sustainable Development. New York, 2003.

Revising indicators of sustainable development: status and options. New York: UN CSD 2006.

UNDP. United Nations Development Program. Human development reports series. New York: Oxford University Press, 1990, 1994, 1996 e 2000.

WACKERNAGEL, M. et al. Ecological Footprint of Nations. Alana: Center for Sustainability Studies, March 1997.

WORLD BANK. World development report 2000/2001. Washington: World Bank, 1996, 2000, 2001 e 2002. Disponível em: <http://worldbank.org >. Acessado em: 6 maio 2002.

\section{SOBRE 0 AUTOR}

\section{Osmar Siena}

Departamento de Administração - Universidade Federal de Rondônia (UNIR)

Centro de Estudos para o Desenvolvimento Regional (CDR)

End.: Campus José Ribeiro Filho - BR 364 - Km 9,5 Sentido Acre - CEP 78.900-000

Tel.: (69) 3214-4205; 2182-2228.

E-mails: siena@unir.br; osmar_siena@uol.com.br 